Running head: RESPONSES TO RAPE

\title{
Reader Responses to Literary Depictions of Rape
}

\author{
Emy Koopman
}

Erasmus University Rotterdam [at the time the research was conducted: Utrecht University]

(e.koopman@eshcc.eur.nl) [adjusted]

Michelle Hilscher

University of Toronto

Gerald Cupchik

University of Toronto

[AUTHOR COPY, BEFORE CORRECTED PROOFS]

Prof. Gerald C. Cupchik

Department of Psychology

University of Toronto at Scarborough

1265 Military Trail

Scarborough, ON

Canada M1C 1A4 


\begin{abstract}
This study explored reader responses to different literary depictions of rape. Four literary excerpts were used, divided in aesthetic versus non-aesthetic (STYLE) and allusive versus explicit (DETAIL). The general question was how readers react to literary fragments depicting rape and whether the level of aesthetics and the level of explicitness influenced readers' thoughts and feelings. An open-ended question asked readers to report how the style had influenced their thoughts and feelings, while 7-point scales addressed the following variables: experienced distance, perceptions of realism and of beauty, emotional versus intellectual reaction, empathy, tension, and arousal. In a 2 (DETAIL: explicit vs. allusive) x 2 (STYLE: aesthetic vs. nonaesthetic) within-subjects design $(\mathrm{N}=34)$, gender functioned as a between-subjects variable. Results indicate that the personal tendency to feel engaged with fiction overrides effects of aesthetics and explicitness. Factor analysis suggests that readers who are easily engaged with the characters feel unsettled when reading rape scenes they find brutal and intellectualize in order to handle these feelings. These 'high empathizers' are not likely to be detached or to appreciate the fragment negatively: once absorbed, they will try to take something positive even from an unsettling experience.
\end{abstract}

Keywords: literary representations, rape, sexual violence, explicit, allusive, aesthetic distance, empathy 


\section{Reader Responses to Literary Depictions of Rape}

The recent trial of convicted rapist and murderer Russell Williams in Belleville, Ontario resulted in news stories that stood out for their graphic description of the rapes and murders of his victims. A controversy ensued, as summarized by Pat Hewitt in the October $19^{\text {th }}, 2010$ issue of The Toronto Star: "while some can't get enough, others are asking why the public needs to know so much about the horrifying sexual assaults, rapes and murders." Contrasting the sides of this debate in an online editorial on Sympatico.ca News, Bolton and Syrovy (2010) pitted journalists' responsibility to report the full story, "in all its raw and gut wrenching form" with the shock value of going too in an effort to sell papers.

News stories reporting on the details of sexual violence can elicit fear responses in readers because they describe the victim's injuries and that individual's endangerment and fear (Bartlett \& Gentile, 2011). Developmental research by Valkenburg, Cantor, and Peeters (2000) suggests that adults are more scared of realistic depictions of war and suffering than of fantasybased media depictions of surreal events. Their data show that cognitive re-appraisal is the most frequent response to realistic fear depictions. However, the predominant form of coping response demonstrated by readers of newspaper articles detailing sexual violence is unknown. It may be that these graphic articles are too unsettling, causing readers to turn away from the realities of assault and sexual violence. Literary depictions of sexual violence, on the other hand, might present these episodes in a way that enable readers to address the underlying issues. These fictional narratives offer a balance between detailed realistic accounts of horrific events and the psychological experiences of the victim and motivations of the assailant.

Upon turning to research about representations of sexual violence it becomes clear that this type of depiction is a specific concern within media studies. Yet, upon looking at the research conducted in this field, it is obvious that literary depictions and aesthetic features are 
greatly overlooked. Earlier studies used audiovisual or audiotaped rather than literary depictions of rape and attempted to determine whether these scenes heightened viewer arousal (e.g. Abel, Barlow, Blanchard \& Guild, 1977; Barbaree, Marshall \& Lanthier, 1979; Farkas, 1979; Schmidt, 1975). When it comes to audiovisual rape scenes, Malamuth, Heim, and Feshbach (1980) and Malamuth and Check (1980) have demonstrated that, for most participants, the decisive variable is (involuntary) arousal in the victim: non-deviant participants became highly aroused only when they believed that the depicted victim was sexually aroused herself (as is commonly the case in pornographic depictions).

Our concern with representations of rape is not simply whether and how they arouse people, but to what extent different ways of depicting these scenes of suffering and violence influence a myriad of reader responses, particularly those concerning the experienced distance from or engagement with the scene and characters. Approaching the topic of rape representations from the viewpoint of empirical aesthetics implies exploring how aesthetic features mediate responses to gruesome and violent scenes. This is an important ethical debate within the humanities (e.g. Nussbaum, 1995; Sontag, 2003). Highly aestheticized representations of suffering are typically criticized for taking the edge off suffering, doing an 'injustice' to actual victims (e.g., Adorno, 1977). On the other hand, writers like Toni Morrison have argued that, without aestheticization, the reader would not be able to bear an encounter with the other's suffering (in Taylor-Guthrie, 1994).

In the case of depictions of sexual violence, the dynamics between aesthetic features and audience response is particularly troublesome ethically, since the sexual aspect may already trigger erotic desires and an aesthetic depiction could be expected to increase these desires. Gaining more insight into these dynamics can help us understand under which conditions horrific literary depictions trigger socially desirable responses like empathy, intellectual reflection, and 
stylistic appreciation, or socially less desirable responses like sadism or sexual desire. More generally, the current study can contribute to theory-building regarding the issue of aesthetic distance, the way beauty either pushes readers away or draws them in.

A relevant earlier study was conducted by Barker (2007) for the British Board of Film Classification (BBFC). Barker used five movies with sexual violence, two of which had a specific art house appeal and artistic cinematography (À ma Soeur and Irréversible), to find out what determines people's positive or negative responses to cinematographic sexual violence. The audiences had encountered these movies under natural circumstances, having seen them before participating in the study. Barker first surveyed how the films were talked about on internet forums, then mounted a web questionnaire, and eventually interviewed people in twenty person focus groups. All of these measures led to the conclusion that audience comments were distinct for the different films. Disregarding a subgroup of people with a general preference for horrific violence, appreciation depended on the context. Just looking at the two art house films, it could be concluded that the people who appreciated them ('embracers') tried to find meaning in the events, relating the sexual violence back to the context of the entire film and generally demonstrating an intellectualizing response. Moreover, embracers appreciated that the events were portrayed realistically and (in the case of Irréversible) that the director did not shy away from showing the brutality of rape, a fact that people who did not appreciate the film ('refusers') found too gruesome. In the case of Irréversible, embracers also positively appraised the form and structure of the film (the 'style'), while refusers found the style of the film to be 'a gimmick'. Barker's study demonstrated that people can have quite opposing responses to representations of sexual violence and that both the explicitness of the scene and the aestheticization of the scene can lead to either appreciation or rejection. Barker's study did not systematically compare people's responses to more or less explicit and aestheticized portrayals of sexual violence. 
Like their cinematic counterparts, literary depictions of rape tread a fine line between art and pornography. In this respect, Higgins and Silver (1991) described a 'double bind': authors giving a (detailed) depiction of a rape scene run the risk of inviting sexual desire but, if rape is not represented at all, that would deny the experiences of rape victims. Authors have found various solutions to dealing with problems representing the traumatic experience of rape. Authors might describe rape either in an explicit or in an allusive manner. An 'explicit' depiction gives readers full access to the scene, showing them the violent actions and phrases, and does not shy away from mentioning genitals and sexual actions. 'Allusive' depictions, on the other hand, veil the act of rape and circle around it, either by using metaphoric language or by concentrating on the setting or the aftermath - practically showing anything but the rape itself. The other main distinction that could be made is between rape scenes which are aestheticized, using poetic language (that is: using a lot of imagery and striking repetitions or contrasts), and those which are more realistic and straight-forward. Those 'non-aesthetic' scenes do not overtly use poetic images, but instead apply more common, everyday language. Rape depictions thus differ in 'detail', in how much one sees of the rape (explicit vs. allusive) and in 'style', in how the rape is presented (aesthetic vs. non-aesthetic).

Two central concepts related to the reading of rape depictions are empathy and aesthetic distance which should be inversely correlated. Empathy is commonly defined as the ability to experience and understand another person's affective or psychological state, the ability to imagine oneself in someone else's shoes (e.g. Krebs, 1970; Zahn-Waxler \& Radke-Yarrow, 1990; Preston \& de Waal, 2002; Argo, Zhu \& Dahl, 2008). It is often a spontaneous response that, as Keen (2006) has put it "can be provoked by witnessing another's emotional state, by hearing about another's condition, or even by reading" (p. 208). According to Keen (2006), it is thus important to take 'personal distress' into account when considering the dynamics between 
literature (or fiction in general) and empathy. This distress may negatively impact readers' appreciation of the aesthetics of the rape narrative. That negative appraisal, accordingly, may also cause readers to engage critically with the narrative, but it could also lead them to refuse to give it any further thought.

Aesthetic distance, first termed "psychical distance" by Bullough (1912) in his seminal article, is determined by an interaction between the evocative qualities of a stimulus situation and the disposition of the viewer. According to Bullough (1912) "[d]istance is decreased to the extent that subject matter reminds us of our everyday lives" (p. 168); while "salient stylistic qualities remove the work from the everyday world" and thus increase distance (p. 169). Thus accounts of rape which are highly realistic and detailed should decrease aesthetic distance, whereas those with salient stylistic features should increase it. In this case, when confronted with the realities of sexual assault, we would expect participants to adopt a distant and intellectualized approach. This would accord with Lazarus and Alfert (1964) who showed that intellectualization reduced stress for participants who viewed a circumcision film. When given a matter-of-fact anthropological commentary, they experienced significantly less emotional distress than when they were shown the same circumcision with a narrator telling about the trauma of the event. Cupchik and Wrobleski-Raya (1998) also found that when "lonely" participants were asked to identify with solitary figures depicted in paintings, they favored the style over subject matter which underscored the arousal reducing value of intellectualization.

This study examined readers' thoughts and feelings about the characters and events in four literary fragments of episodes representing a combination of the two variables of potential interest: Explicit versus Allusive description of the rape scene which is presented either in an Aesthetic or Non-aesthetic manner. While it would have been ideal to have two examples for each of the four cells, we could not expect a participant to read eight literary accounts of rape. 
The readers, male and female undergraduate and graduate students, were permitted to drop out of the study at any point. Both quantitative and qualitative data were collected to gain insight into how readers addressed these emotionally challenging texts. Verbal rating scales measured: experienced distance (from the scene), empathy with the victim, perception of the perpetrator, evocation of feelings versus evocation of thoughts (emotional versus intellectual reaction), tension, arousal, and (aesthetic) appreciation, and whether they wanted to continue reading the rest of the text. Qualitative data were obtained by asking participants after they read each fragment: "How do you think the style influenced your feelings and thoughts about the characters and events?" A thematic content analysis was applied to these comments and the frequency of each category was determined for each participant and fragment. This numerical transformation made it possible to explore relations between the two kinds of data.

\section{Method}

\section{Participants}

Graduate and undergraduate students, as well as former undergraduate and graduate students and exchange students in Toronto (Canada) were approached personally with the question whether they would be willing to participate in a study on literary representations of sexual assault. The voluntary basis of participation was emphasized. People were told not to participate if they felt reading these materials might affect them too strongly. Participants also had the option to stop reading at any time. Six participants dropped out of the study because they found the materials too intense, these participants did not provide us with the exact point where they stopped reading. Two other participants stopped reading during one of the explicitly violent fragments. All participants were asked to provide us with the following demographic information: age, gender, education and whether English was their first language. 
The final sample consisted of 34 participants: 13 male, 21 female; 21 graduate students, 13 undergraduates. For 19 participants, English was their first language, for the other 15 it was not. The average age was 24.5 (SD: 3.01), the youngest respondent was 19, the oldest 31 . Participants took the booklet with the fragments and questions home, allowing them to complete the questionnaire in an atmosphere they themselves found comfortable. There was no time limit on how long they could take for the readings.

\section{Materials and Procedure}

The study had a 2 (DETAIL: explicit vs. allusive:) x 2 (STYLE: aesthetic vs. nonaesthetic) within-subjects design, requiring participants to read all four literary fragments. Between-subjects variables were gender and education (undergraduate versus graduate students). Participants were provided with a booklet containing four literary fragments of two pages each. These four fragments were chosen after considerable research on novels including rape scenes and after careful debate between the authors of this article. The fragments were chosen out of a larger number of 22 fragments, on account of being good examples of either an explicit or allusive and of an aestheticized or relatively less aestheticized fragment. Moreover, all of the authors and victims in the fragments were female and all of the excerpts were or could easily be shortened to approximately 1500 words. To control for order effects, the fragments were put in the booklets in random order.

Rating scales. After reading each fragment, participants responded to the following 7point Likert scales:

1. Detached versus Engaged with the scene ( $1=$ completely detached, $7=$ completely engaged)

2. Empathy with the victim ('To what extent could you feel the emotions of the $\operatorname{victim}(\mathrm{s})$ ?': $1=$ not at all, $7=$ to a great extent)

3. Awareness of the perpetrator(s) ('To what extent could you feel the drive of the perpetrator(s)?': $1=$ not at all, $7=$ to a great extent) 
4. Perception of stylistic beauty $(1=$ not at all stylistically beautiful, $7=$ very stylistically beautiful)

5. Focus on style or events ( $1=$ mainly on style, $7=$ mainly on events $)$

6. Perception of realism $(1=$ completely implausible, $7=$ very plausible $)$

7. Experience of tension ( $1=$ not at all tense, $7=$ extremely tense)

8. Feelings versus Intellectual response ('Did the excerpt primarily evoke feelings or thoughts?': 1 = primarily feelings, 7 = primarily thoughts)

9. Repulsion versus Arousal ( $1=$ primarily repulsive, $7=$ primarily arousing)

10. Moral Indignation versus Sexual Fantasy ('Did you think the focus of the writer is on causing moral indignation or on describing a sexual fantasy?': 1= causing moral indignation, $7=$ describing sexual fantasy)

11. Fiction/Aesthetic attitude ('Did it make a difference for your experience of the fragment that you knew it was fiction?': 1= not at all, $7=$ very much so)

12. Read More ('After reading this excerpt, would you like to read more of the novel?': $1=$ not at all, $7=$ very much so)

After completing the rating scales participants were instructed to answer the following question: 'How do you think the style influenced your feelings and thoughts about the characters and events?' These responses were submitted to a thematic qualitative analysis which yielded categories that could be enumerated and related to the quantitative scales through a combination of factor analysis and correlations.

Excerpts. The excerpts were derived from the following novels: Sylvie Germain's The Medusa Child (A), Gloria Naylor's The Women of Brewster Place (B), Joyce Carol Oates'We Were the Mulvaneys (C), and Virginie Despentes'Baise-Moi (D). The conditions of the fragments could not be kept completely similar as the number of characters and their ages, the precise amount of violence, the setting, the amount of direct or indirect speech, all these variables differed. However, we expected the variables of explicitness, allusiveness, and aestheticization to be salient enough to produce effects regardless of variation in other aspects of the narratives.

\section{Excerpt A: Allusive - Aesthetic}

This scene starts with a poetic description of light that "cleanses itself of night's last traces" and continues to describe the rape of a young girl by her stepbrother (whom the narrator 
designates by the name 'the Ogre') through metaphors and similes and an extensive use of emotive adverbs. The second part of this excerpt carries a few more references to violence, but remains within an aestheticized discourse.

\section{Excerpt B: Explicit - Aesthetic}

The excerpt from Naylor's novel portrays gang rape in an extremely explicit manner, containing detailed descriptions of the violent sexual act(s) and particularly of the bodies of the victim and perpetrators, e.g.: "He slammed his kneecap into her spine and her body arched up, causing his nails to cut into the side of her mouth to stifle her cry." However, as can already be discerned from the choice of words in the aforementioned sentence ('arched up,' 'stifle'), Naylor makes use of a poetic discourse to transmit these events. Naylor uses repetitions, prefers poetic words to more common ones and makes extensive use of metonyms.

\section{Excerpt C: Allusive - Non-Aesthetic}

Oates' novel eludes the rape scene itself and instead describes the experiences of a teenage girl after she has been raped. The result is a realistic scene of protagonist Marianne's attempts to clean up any signs and act like nothing has happened. Straight-forward descriptions of 'cleansing' are interspersed with Marianne's thoughts of school events and flashbacks to the rape, mainly sentences the rapist said to her, represented in cursive. This excerpt can be characterized as allusive and non-aesthetic. While the realistic descriptions of the stained dress and the washing of this dress can easily be interpreted as metaphoric, the realistic details (e.g. 'Pond's complexion soap') and concerns of Marianne work against the impression that Oates is pushing a metaphoric, aestheticized account.

\section{Excerpt D: Explicit - Non-Aesthetic}

Despentes' excerpt can be characterized as the most 'crude' and straightforward, combining explicitness, violence and realism. The scene is set in the suburbs of Paris and 
Despentes uses the appropriate slang which in the English translates to words like 'mugs' (for faces), and 'pronged' (for sexual intercourse). The rape victims are two girls, Manu and Karla. The focalization lies entirely with Manu, who is, as the first paragraph makes clear, a tough, nononsense kind of girl with no ambitions beyond having sex and getting drunk. An example of Despentes' realistic and explicit depiction: 'Now another guy gets on top of Manu; before lying down, he makes her spread her legs more by kicking the inside of her thighs. She watches the sky. She waits. When he's inside her, he says, "Move that ass, so you can really feel how good I fuck you.",

\section{Results}

\section{ANCOVAs - Quantitative}

A series of ANCOVAs were executed in order to find out whether DETAIL (allusive versus explicit) and STYLE (aesthetic versus non-aesthetic) variables affected the rating scale items. The subject variables education (graduate or undergraduate) and whether English was the participants' first language were treated as covariates. Gender was treated as a between-subjects variable. While there were a number of interesting interaction effects, these are not presented because of the limited representation of literary excerpts in each of the four cells in the design (1 per cell).

There was a significant main effect of STYLE, $F(1,30)=7.01, p<.05$, which showed that participants experienced the 'aesthetic' excerpts as stylistically more beautiful than the nonaesthetic excepts (see Table 1). There also was a significant main effect of DETAIL on stylistic beauty, with readers perceiving the allusive excerpts as much more beautiful than the explicit ones, $F(1,30)=8.82, p<.01$. A significant main effect of DETAIL was also found on the item that measured focus on events (versus focus on style), $F(1,30)=5.20, p<.05$. Readers were focused much more on events than on style when reading the explicit fragments. Readers were 
also more aware of the perpetrator's drive when reading the explicit compared with the allusive fragments, $F(1,30)=4.22, p<.05$. The Detail variable therefore was found to have more impact on readers than the Style variable with the explicit situation drawing the attention of readers.

Insert Table 1 about here

\section{Deriving Qualitative Categories}

Two coders independently categorized the responses to the open question, leading to ten categories:

1. Style: remarks on the literariness or stylization of the excerpt, including remarks on specific stylistic devices. E.g.: 'This excerpt is a lot more stylistic than the last'.

2. Directness: remarks on the directness/realism of the excerpt, by stressing the transparency/straightforwardness of the style, or the way descriptions correspond to actual situations. E.g.: 'The style is very straightforward and clear-cut'.

3. Brutality: remarks on horror or brutality (or related terms, like 'force' or 'crude') of the events and/or the characters' behaviour, or the depiction in general. E.g.: 'The style with the rough descriptions was very brutal'.

4. Positive appraisal: remarks of appreciation of the style, the fragment as a whole, or the way style and content fit together. E.g. 'I was fascinated by description and style'.

5. Negative appraisal: remarks that the style misses the mark, is not 'effective,' or other negative appraisals of the excerpt. E.g.: 'The cliché phrases were distracting and lent an air of artificiality or distance/anonymity to the text'.

6. Intellectual response: remarks that the excerpt evoked thoughts, or the response is largely or mainly intellectual, giving a critical reflection on the issue of rape. E.g.: 'it probes me to reflect more on the rape problem'.

7. Curiosity: remarks that the passage was not completely clear, leaving room for one's own imagination; there is a need to know more about the context or characters. E.g.: 'I was actually curious to find out more as I read it'.

8. Detachment: remarks of not feeling able to engage with the scene, and/or failing to sympathize with the characters; general distance between reader and scene. E.g.: 'it made me feel both separated from the characters and unconnected to them'.

9. Engagement: remarks of feeling engaged with the scene and being able to sympathize or empathize with characters. E.g.: 'I could feel Manu's emotions and point of view'.

10. Disquiet: remarks expressing (physical or emotional) disgust, nausea, anger, shock, or other strong emotions of being upset. E.g.: 'My own response was anger, repulsion and disgust and I feel as if these three emotions were triggered by the violence of the rape'. 
To establish interrater reliability, Pearson correlations were calculated by category between raters on the sampled participant narratives and the correlation coefficients were all greater than .73 . The sampling was carried out by randomly selecting four participant responses to each of the four excerpts for each of the ten categories.

\section{ANCOVAs - Qualitative}

Results on the qualitative measures were very strong and consistent with those obtained on the quantitative measures, as can be seen in Table 2. First of all, similar to the scale item on 'stylistic beauty', both STYLE and DETAIL had a significant main effect on the qualitative construct 'Style'. In terms of STYLE, aesthetic fragments gave rise to more stylistic comments than did non-aesthetic ones, $F(1,30)=8.11, p<.008$, and in relation to DETAIL, allusive fragments elicited more stylistic comments than did explicit ones, $F(1,30)=33.95, p<.001$.

Significant main effects of DETAIL were found on the constructs 'Brutality', $F(1,30=$ 26.52, $p<.001$, and 'Curiosity', $F(1,30)=22.21, p<.001$. That the fragments which were judged to be 'allusive' in the stimulus selection process (Germain's and Oates') were also seen as evoking more curiosity by the respondents serves as a manipulation check. That the explicit fragments (Naylor's and Germain's) were deemed more brutal was also to be expected.

Insert Table 2 about here

\section{Factor Analysis - Quantitative}

A factor analysis was conducted in order to find out which quantitative scale items clustered, using varimax rotation to maximize the difference between factors (see Table 3). The within-subjects design of the study made for a relatively stable factor matrix because the average 
rating for each scale was determined by four judgments. Four factors were derived with eigenvalues greater than 1.00 that explained $71.29 \%$ of the total variance: Factor 1 explained $30.30 \%$, Factor 2 explained 14.55\%, Factor 3, 14.14\%, and Factor 4, 12.30\% of the total variance.

Factor 1, Emotional Absorption, had factor loadings greater than .50 on five scales: engagement (.90), experiencing the victim's emotions (.88), experiencing tension (.78), concentrating on events instead of on style (.76), and rating the excerpt as having high realism (.50). For example, one respondent said, about Naylor's explicit-aesthetic fragment: 'I found that the highly realist style worked to draw me into the narrative, and to become attuned to the physical environment in which the rape took place, and also to attend to Lorraine's corporeality.'

Factor 2, Aesthetic Appreciation, was primarily characterized by participants appreciating the style of the excerpt. They were responsive to the perceived fictional quality of the text (.70), tended to rate the scene as highly realistic (.63), and wanted to read more (.56). Factor 3 , Arousal, reflected the perception of the text as describing a sexual fantasy (.78) that stimulated arousal (.78). While this factor suggested a sexual response to the rape depictions, an inspection of the mean scores on these scales showed that readers did not score high on any of them which is not surprising given the social undesirability of responding to rape depictions with arousal. Only one of the respondents admitted to arousal, in response to Despentes' explicit-non-aesthetic fragment: 'My feeling is of general revulsion but also mild arousal.' Factor 4, Intellectual Provocation, was a response characterized thinking (.81) and feeling the drive of the perpetrator (.75), perhaps an effort to understand the motives of the perpetrator by imaginatively stepping into his shoes. 
Insert Table 3 about here

\section{Factor Analysis - Qualitative}

A factor analysis was conducted in order to find out which qualitative categories clustered, using varimax rotation to maximize the difference between factors (see Table 4). This analysis led to three factors with eigenvalues greater than 1.00 which explained $70.69 \%$ of the total variance: Factor 1 accounted for $29.95 \%$, Factor 2, $21.33 \%$, and Factor 3, $19.42 \%$ of the total variance.

The first factor, Positive Response, consisted of positive appraisal (.90), engagement (.89), style (.80), directness (.65) and intellectual response (.52). A favorable response and absorption in the text went hand in hand with an appreciation of its style and realism. The second factor, Unsettled Response, consisted of disquiet (.77), brutality (.75), intellectual response (.63) and curiosity (.58). It was to be expected that higher brutality in the scene would go together with feeling more unsettled, and apparently this also related to greater intellectual reflection perhaps as a defensive response. The third factor, Negative Response, consisted very clearly of negative appraisal (.93) and detachment (.93), which may have been a way of handling the negative emotional response.

Insert Table 4 about here

\section{Correlations between Quantitative and Qualitative Factors}

The correlation results showed how quantitative and qualitative data can be mutually reinforcing. Quantitative Factor 1, Emotional Absorption, correlated positively with Qualitative 
Factor 2, Unsettled Response, $r=.35, p<.04$, and negatively with Qualitative Factor 3, Negative Response, r: $-0.34, \mathrm{p}<.05$. As would be expected, the more readers become emotionally and empathically absorbed in texts which described sexual assault (Quantitative Factor 1), the more emotionally unsettled their accounts were of how the texts affected their thoughts and feelings about the characters and events (Qualitative Factor 2). However, as might also be expected in a literary context, the more readers become emotionally absorbed in accounts of sexual assault which were presented in a literary way (Quantitative Factor 1), the less was their negative appraisal and disposition to become detached from the text and the reading process more generally (Qualitative Factor 2).

Quantitative Factor 2, Aesthetic Appreciation, correlated positively with the Qualitative Factor 1, Positive Response, $r=.35, p<.04)$. This follows from the previous correlation in that the more readers responded to the fictional realism and beauty of texts which may prompt them to want to read on (Quantitative Factor 2), the more this was reflected in a positive appraisal and engagement in the style of the work (Qualitative Factor 1).

\section{Discussion}

In a review of printed news stories about sexual assault, Naylor (2001) makes reference to their obvious "negative and graphic consequences ....[that]...permit highly sexualized and individualized representation, with reporting paralleling violent and/or pornographic voyeuristic representations (p. 185)." Thus, while sexual assault stories draw attention to dangers in an urban setting, they might also stimulate vicarious and hidden excitement. It is in this context that we consider the value of literary depictions of rape which seek to encourage reflection and perhaps even conversation about the topic. For this reason we chose literary narratives as stimuli that varied in the extent to which they focused directly on the assault event or were more circumspect and which varied in the importance of aesthetic style. On the response side, we obtained ratings 
of the excerpts on scales that measured different aspects of response to the narratives as well as accounts of how participants thought that the style influenced their feelings and thoughts about the characters and events.

The stimulus variables had the predicted effects on perceptions of the excerpts. The "aesthetic" and "allusive" treatments were judged to be most beautiful. Further, the "explicit" fragments focused the readers' attention on the events and the perpetrator's drive. No other main effects were obtained. The real empirical story has to do with the response side of things, both in terms of the quantitative scales and the qualitative categories. The factor analyses revealed different facets of how readers responded to the text and the characters whose actions and experiences were depicted in them. In terms of the quantitative rating scales, there were four meaningful factors. Factor 1 involved Emotional Absorption and an empathic response to the victim's emotions stimulated by the ongoing events. This replicated the absorption factor obtained in an earlier study (Braun \& Cupchik, 2001) when readers engaged in a "close reading" of literary texts that combined emotion and sensory awareness. Factor 2, Aesthetic Appreciation, provided an account of what makes readers want to continue reading a novel text. It encompassed the fictional quality of the texts that combined realistic depiction of a scene with stylistic elegance. As might be expected given the unifying theme underlying the excerpts, Factor 3, Arousal, related to perceived sexual fantasy and the related stimulation of arousal. Factor 4 was related to an awareness of the drive of the other main character[s] in the narratives which stimulated thoughts about possible motivations.

The qualitative analysis yielded a potent set of categories which further explored the structure of literary experiences. Factor 1, Positive Appraisal, showed that engagement was shaped both by style and a realistic account of events which stimulated reflection on the texts. As might be expected, Factor 2, Unsettled Response, reflects an attempt to come to terms affectively 
with the brutal nature of these assault narratives. Factor 3, Negative Appraisal, shows that detachment and aesthetic distance can serve as a means of dealing with the assault stories. These data therefore provide a Reader Response example of the defensive strategies described by Lazarus and Alfert (1964) as a means of handling stressful film depictions of circumcision rights. The high point of the data analysis involved the three significant correlations which revealed a complementary interface between the quantitative and qualitative data. First, the more absorbed readers were in the narratives (Quantitative Factor 1), the greater their experiences of unsettled emotion (Qualitative Factor 2). But, at the same time, absorption in the narrative (Quantitative Factor 1) diminished any negative appraisal and consequent detachment from the text (Qualitative Factor 2). This is also consistent with the earlier finding that texts which were challenging and rich in meaning about life engaged subjects who slowed the reading process to glean as much from the texts as possible (Cupchik \& Laszlo, 1994). The third correlation shows an important difference between news story and literary descriptions of sexual assault. Fictional realism and perceived beauty of the texts motivated readers to want to read on to complete the fragment and this, of course, was a basis for positively appraising the texts and their style.

In summary, this study challenged both the authors and readers to confront the realities of sexual assault as presented from a literary perspective. While tabloid accounts of rape may focus on lurid details and verge on the pornographic, literary depictions attempt to take this horrific theme to a higher plane wherein readers can empathize with the experiences of the victims and try to figure out motives of the perpetrator[s]. Stylistic variations in terms of directness/allusiveness and aestheticization shape the aesthetic distance of readers and make it more or less possible to engage the text. Style helps to effect the delicate balance between being drawn into the text by the emotional experiences of victims and a desire to withdraw in the face 
of personal and physical assault. It is this challenge which lies at the heart of the aesthetic process as an attempt to address the realities of life in their many forms. 


\section{References}

Abel, G.G., Barlow, D.H., Blanchard, E., \& Guild, D. (1977). The components of rapists'sexual arousal. Archives of General Psychiatry, 34, 895-903.

Adorno, T. W. (1977). Kulturkritik und gesellschaft. In R. Tiedemann (Ed.), Gesammelte schriften band 10-1: Prismen: Kulturkritik und gesellschaft I (pp. 11-30). Frankfurt am Main: Suhrkamp.

Argo, J.J., Zhu, R., \& Dahl, D.W. (2008). Fact or fiction: An investigation of empathy differences in response to emotional melodramatic entertainment. Journal of Consumer Research, 34, 614-623.

Barbaree, H.E., Marshall, W.L., \& Lanthier, R.D. (1979). Deviant sexual arousal in rapists. Behaviour Research and Therapy, 17, 215-222.

Barker, M., Mathijs, E., Sexton, J., Egan, K., Hunter, R., \& Selfe, M. (2007). Audiences and receptions of sexual violence in contemporary cinema. British Board of Film Classification (BBFC).

Bolton, G., \& Syrovy, D. (2010, October 22). Russell Williams media coverage: How much is too much and how far is too far? Sympatico.ca News. Retrieved from http://news.sympatico.ca/oped/coffee-talk/russell_williams_media_coverage_how _much_is_too_much_and_how_far_is_too_far/74066ed9

Braun, I. \& Cupchik, G. C. (2001). Phenomenological and quantitative analyses of absorption in literary passages. Empirical Studies of the Arts, 19(1), 85-109.

Bullough, E. (1912). 'Psychical distance' as a factor in art and as an aesthetic principle. British Journal of Psychology, 5, 87-98.

Chismar, D. (1988). Empathy and sympathy: The important difference. Journal of Value Inquiry, 22, 257-266. 
Cupchik, G.C. (2001). The evolution of psychical distance as an aesthetic concept. Culture \& Psychology, 8, 155-187.

Cupchik, G. C. \& Laszlo, J. (1994). The landscape of time in literary reception: Character experience and narrative action. Cognition and Emotion, 8, 297-312.

Cupchik, G.C., \& Wroblewski-Raya, V. (1998). Loneliness as a theme in painting. Visual Arts Research, 24(1), 65-71.

Despentes, V. (2002). Baise-moi (B. Benderson, Trans.). New York: Grove Press.

Farkas, G. M. (1979). Trait and state determinants of male sexual arousal to description of coercive sexuality. Doctoral dissertation, University of Hawaii.

Germain, S. (1994). The medusa child (L. Nash, Trans.). Sawtry, Cambs.: Dedalus.

Hewitt, P. (2010, October 19). Do we need to know all the details of Williams' crimes? The Toronto Star. Retrieved from http://www.thestar.com/news/canada/article/877982--dowe-need-to-know-all-the-details-of-williams-crimes

Higgins, L. A., \& Silver, B.R. (1991). Rape and representation. New York: Columbia University Press.

Keen, S. (2006). A theory of narrative empathy. Narrative, 14, 207-236.

Krebs, D. L. (1970). Altruism: An examination of the concept and a review of the literature. Psychological Bulletin, 73, 258-302.

Lazarus, R.S., \& Alfert, E. (1964). Short circuiting of threat by experimentally altering cognitive appraisal. Journal of Abnormal \& Social Psychology, 69, 195-205.

Malamuth, J.V.P., \& Check, N.M. (1980). Penile tumescence and perceptual responses to rape as a function of victim's perceived reactions. Journal of Applied Social Psychology, 10, 528-547. 
Malamuth, J.V.P., Heim, M., \& Feshbach, S. (1980). Sexual responsiveness of college students to rape depictions: Inhibitory and disinhibitory effects. Journal of Personality and Social Psychology, 38, 399-408.

Naylor, B. (2001). Reporting violence in the British print media: Gendered stories. The Howard Journal of Criminal Justice, 40(2), 180-194.

Naylor, G. (1982). The women of Brewster place. New York: Viking Press.

Nussbaum, M. C. (1995). Poetic justice: The literary imagination and public life. Boston: Beacon Press.

Oates, J.C. (1996). We were the Mulvaneys. New York: Dutton.

Preston, S.D., \& de Waal, F.B.M. (2002). Empathy: Its ultimate and proximate bases. Behavioral and Brain Sciences, 25, 1-72.

Schmidt, G. (1975). Male-female differences in sexual arousal and behavior. Archives of Sexual Behavior, 4, 353-364.

Sontag, S. (2003). Regarding the Pain of Others. New York: Farrar, Straus and Giroux.

Taylor-Guthrie, D. (1994). Conversations with Toni Morrison. Jackson: UP of Mississippi.

Valkenburg, P.M., Cantor, J. \& Peeters, A.L. (2000). Fright reactions to television: A child survey. Communication Research, 27, 82-97.

Zahn-Waxler, C., \& Radke-Yarrow, M. 1990). The origins of empathic concern. Motivation and Emotion, 14, 107-30. 


\section{Tables}

Table 1

Main Effects Quantitative ANCOVA

\section{Style}

Detail

Aesthetic Non-aesthetic Allusive Explicit

\begin{tabular}{lcccc} 
Stylistically beautiful & M: 4.70 & $3.75^{*}$ & 5.10 & $\begin{array}{l}3.37^{* *} \\
\end{array}$ \\
& SD: 0.11 & 0.15 & 0.17 & 0.16 \\
Focus on events rather than style & M: 4.72 & 5.04 & 4.28 & $\begin{array}{l}5.48^{*} \\
\end{array}$ \\
& SD: 0.20 & 0.22 & 0.19 & 0.23 \\
Focus on perpetrator's drive & & & & \\
& M: 3.32 & 2.73 & 2.54 & $3.51^{*}$ \\
& SD: 0.30 & 0.23 & 0.27 & 0.30 \\
\hline
\end{tabular}

Table 2

Main Effects Qualitative ANCOVA

\section{Style}

Aesthetic Non-aesthetic Allusive Explicit

Style

Brutality

Curiosity
M: 3.06

SD: 0.38

M: 1.10

SD: 0.19

M: 0.67

SD: 0.14
$2.18 * *$

0.39

0.87

0.15

$0.48 *$

0.12
3.33

$0.41 \quad 0.32$

$0.49 \quad 1.47 * * *$

$0.12 \quad 0.16$

$1.08 \quad 0.07 * * *$

$0.21 \quad 0.05$

$* p<.05 * * p<.01 * * * p<.001$ 
Table 3

Factor Analysis of Quantitative Scale Items

Factor and Eigenvalue

Item

Loading

1 Emotional Absorption

Engaging

.90

3.64

Empathy victim

.88

Tension

.78

Focus on events

.76

Realism

2 Aesthetic Appreciation

Fiction

.76

1.75

Realism

.63

Stylistic beauty

.60

Read more

.56

3 Arousal

Sexual fantasy

.87

1.70

Arousal

.78

4 Intellectual Provocation

Thoughts

.81

1.48

Perpetrator's drive

.75

Table 4

Factor Analysis of Qualitative Categories

Factor and Eigenvalue

Item

Loading

1 Positive Response

Positive appraisal

.90

2.99

Engagement

.89

Style

.80

Directness

2 Unsettled Response

Disquiet

.77

2.13

Brutality

.75

Intellectual Response

.63

Curiosity

.58

3 Negative Response

Detachment

.93

1.94

Negative appraisal

.93 